2017-05

Trace elements in fragments of fishing net and other filamentous plastic litter from two beaches in SW England

Turner, Andrew

http://hdl.handle.net/10026.1/8745

10.1016/j.envpol.2016.11.034

Environmental Pollution

Elsevier BV

All content in PEARL is protected by copyright law. Author manuscripts are made available in accordance with publisher policies. Please cite only the published version using the details provided on the item record or document. In the absence of an open licence (e.g. Creative Commons), permissions for further reuse of content should be sought from the publisher or author. 


\title{
Trace elements in fragments of fishing net and other filamentous plastic litter from two beaches in SW England
}

\author{
Andrew Turner* \\ School of Geography, Earth and Environmental Sciences \\ Plymouth University \\ Drake Circus \\ Plymouth PLA 8AA \\ $U K$
}

Accepted: 11 November 2016

http://dx.doi.org/10.1016/j.envpol.2016.11.034

Embargo period 11 November 2018 


\section{Abstract}

Filamentous plastic litter collected from two beaches in south west England has been characterized by FTIR and XRF. The majority of samples were constructed of polyethylene and consisted of twisted or braided strands of a variety of colours that appeared to be derived from commercial fishing nets. A number of different elements were detected among the samples but, from an environmental perspective, the regular occurrence of $\mathrm{Cr}$ and $\mathrm{Pb}$ and the occasional or isolated occurrence of $\mathrm{Br}, \mathrm{Cd}$ and $\mathrm{Se}$ were of greatest concern. The highest total concentrations of $\mathrm{Br}\left(2420 \mu \mathrm{g} \mathrm{g}{ }^{-1}\right), \mathrm{Cd}$ (1460 $\left.\mu \mathrm{g} \mathrm{g}^{-1}\right), \mathrm{Cr}\left(909 \mu \mathrm{g} \mathrm{g}^{-1}\right), \mathrm{Pb}\left(3770 \mu \mathrm{g} \mathrm{g}^{-1}\right)$ and Se $\left(240 \mu \mathrm{g} \mathrm{g}^{-1}\right)$ were always encountered among orange samples and are attributed to the presence of lead chromates and cadmium sulphoselenide as colourants and to brominated compounds as flame retardants. Element bioaccessibility was evaluated by ICP-MS following an acidic extraction test that mimics the digestive tract of seabirds, with maximum values after a seven-day incubation period and relative to respective total concentrations of 0.2 to $0.4 \%$ for $\mathrm{Cd}, \mathrm{Cr}$ and $\mathrm{Pb}$ and about $7 \%$ for $\mathrm{Br}$. In addition to the welldocumented impacts on wildlife through entrapment, filamentous plastic waste may act as a significant source of hazardous chemicals into the marine foodchain through ingestion.

Keywords: filamentous plastic litter; fishing gear; FP-XRF; heavy metals; bromine; seabirds 
50 Capsule: Many fragments of beached filamentous plastic litter contain elevated

51 concentrations of hazardous elements and pose a chemical threat to wildlife

\section{Introduction}

54 Marine plastic litter is a global problem that has a variety of environmental, social,

55 aesthetic and economic impacts. Amongst the risks of floating, deposited or beached 56 plastics to marine wildlife, the most serious result from entanglement and ingestion.

57 Entanglement may cause suffocation, impair swimming or mobility, disrupt feeding, 58 and result in maiming-amputation and infection (Votier et al., 2011; Lawson et al., 59 2015), while ingestion may obstruct or damage the linings of digestive tracts, reduce

60 feeding drive and lower fat deposition (Verlis et al., 2013; Welden and Cowie, 2016).

61 Filamentous plastic material, including twine, netting, rope, cord, line and fibres, and

62 ranging in length from a few hundred microns to several metres, is particularly

63 significant in these respects, being responsible for the majority of entanglements of 64 many animals (Gilardi et al., 2010; McIntosh et al., 2015) and frequently representing 65 the dominant type of synthetic material retrieved from the digestive tracts of dissected 66 organisms (Devriese et al., 2015; Nadal et al., 2016).

68 Despite the well-documented physical impacts incurred by synthetic filamentous 69 products and fragments, there is little understanding of the chemical makeup of such 70 material, and in particular the presence and mobility of potentially hazardous 71 additives within the polymeric matrix. Inorganic and organic compounds are added to 72 plastics to improve or modify processing, performance, safety, cost, strength, 73 flexibility, appearance, colour, stability and durability, and, aside from reactive 

matrix (Hansen et al., 2010). seabirds.

\section{Materials and methods} backed by shallow, grassy dunes.

organics, such as some flame retardants, are not chemically bound to the polymeric

The present study, therefore, seeks to determine the presence, abundance and bioaccessibility of trace metals, metalloids and other elements that are either intrinsically harmful or that are indicative of harmful substances in samples of filamentous plastic litter collected from sections of two beaches in south west England. A technique based on X-ray fluorescence (XRF) configured in a low-density, 'plastics' mode is employed as a direct, non-destructive means of determining elemental content, while bioaccessibility is evaluated using a physiologically-based extraction test (PBET) that is based on the digestive environment of plastic-ingesting

\subsection{Sampling and sample processing}

Samples were collected from two high-energy, macrotidal, sandy beaches in Cornwall (Figure 1). Whitsand Bay, on the south (English Channel) coast of the county, is located about $10 \mathrm{~km}$ to the west of Plymouth; its expansive, south west-facing beach is backed by steep cliffs that fragment the region at high tide into a series of rocky coves. Constantine Bay is located on the north (Atlantic) coast of the county and about $60 \mathrm{~km}$ to the north west of Plymouth; its arcing, north west-facing beach is

The two beaches were sampled on single occasions and about an hour after high water during the autumn of 2015. Pieces of rope, netting, cord and fishing line that were 
visible to the naked eye were collected by hand from a $\sim 50 \mathrm{~m}$ transect of the high

100 water line, evident from the recent accumulation of macroalgae and debris. Samples

101 were transported in polyethylene zip-lock bags to the laboratory at Plymouth

102 University where they were cleared of sand and algae under running tap water and

103 with the aid of a Nylon brush before being dried at $40{ }^{\circ} \mathrm{C}$ in an oven for about $12 \mathrm{~h}$.

104 Samples were then weighed on a five-figure balance before being stored individually

105 in labelled polyethylene specimen bags and in the dark pending analysis.

106

107

108 The component polymers of the filamentous plastic samples were determined by

109 Fourier transform infra-red (FTIR) spectroscopy using a Bruker ALPHA Platinum

110 attenuated total reflection QuickSnap A220/D-01 spectrometer. Samples were cut to a

111 suitable size using a stainless steel scalpel or scissors before being firmly clamped

112 down on to the ATR diamond crystal. Measurements, consisting of 16 scans in the

113 range 4000 to $400 \mathrm{~cm}^{-1}$ and at a resolution of $4 \mathrm{~cm}^{-1}$, were activated via Bruker OPUS

114 spectroscopic software, and identification involved a comparison of sample

115 transmittance spectra with libraries of reference spectra.

116

118 Samples were analysed for a suite of elements (As, Ba, Bi, Br, Cd, Cl, Cr, Cu, Hg, Ni,

$119 \mathrm{~Pb}, \mathrm{Se}, \mathrm{Sb}, \mathrm{Sn}$ and $\mathrm{Zn}$ ) by energy dispersive field portable-XRF using a battery-

120 powered Niton XRF analyser (model XL3t 950 He GOLDD+) according to protocols

121 described in detail elsewhere (Turner and Solman, 2016) and summarised below.

122 Thus, the instrument was used in the laboratory in a bench-top accessory test stand

123 and was connected to a laptop computer via USB and a remote trigger. The XRF was 
operated in a plastics mode that employs a compensation for mass absorption coefficient based on Compton scatter and corrects for sample thickness down to 0.05 $\mathrm{mm}$. Whole samples, offcuts or sections of monofilamentous material that had been manually intertwined were measured for thickness using digital callipers before being placed on $3.6 \mu \mathrm{m}$ polyester film and positioned centrally and with the measurement surface face downwards over the XRF detector window. On closing the steel shield of the stand, measurements, with appropriate thickness correction, were activated through the laptop for a total period of 120 seconds (60 seconds each at $50 \mathrm{kV} / 40 \mu \mathrm{A}$ and $20 \mathrm{kV} / 100 \mu \mathrm{A})$. Spectra were quantified by fundamental parameters to yield elemental concentrations on a dry weight basis (in $\mu \mathrm{g} \mathrm{g}^{-1}$ ) and a counting error of $2 \sigma$ (95\% confidence) that were downloaded to the laptop using Niton data transfer (NDT) PC software.

\section{Limits of detection, calculated by fundamental parameters, varied according to the} precise density, shape and thickness of sample, but median concentrations ranged from $<10 \mu \mathrm{g} \mathrm{g}^{-1}$ for $\mathrm{As}, \mathrm{Br}$ and $\mathrm{Pb}$ to $>300 \mu \mathrm{g} \mathrm{g}^{-1}$ for $\mathrm{Ba}$ and $\mathrm{Cl}$. Multiple analyses $(n$ = 5) of two Niton reference plastics that had been impregnated with $\mathrm{Br}, \mathrm{Cd}, \mathrm{Cr}, \mathrm{Hg}$ and $\mathrm{Pb}(\mathrm{PN} 180-554$, batch SN PE-071-N) and $\mathrm{As}, \mathrm{Ba}, \mathrm{Cd}, \mathrm{Cr}, \mathrm{Hg}, \mathrm{Pb}, \mathrm{Sb}$ and $\mathrm{Se}(\mathrm{PN}$ 180-619, LOT\#T-18) revealed measured concentrations that were within $10 \%$ of certified values.

\subsection{PBET}

In order to evaluate element bioaccessibility, nine samples of varying colour, appearance and elemental composition (based on XRF analysis) were subjected to a marine avian physiologically-based extraction test (PBET) (Turner and Lau, 2016). 
149 The extraction was modelled on the digestive characteristics of the proventriculus-

150 gizzard (but not the intestine) of the northern fulmar, Fulmarus glacialis, a

151 procellariform known to ingest substantial quantities of plastics, including

152 filamentous waste.

153

154 Briefly, digestive fluid was prepared by dissolving $10 \mathrm{~g}$ of pepsin (lyophilised powder

155 from porcine gastric mucosa; Sigma-Aldrich) into one litre of $0.1 \mathrm{M} \mathrm{NaCl}$ solution

156 and adjusting the $\mathrm{pH}$ by addition of $1 \mathrm{M} \mathrm{HCl}$ to 2.5 . Between 50 and $100 \mathrm{mg}$ of 5 to

$15710 \mathrm{~mm}$ strands of each selected sample, cut with stainless steel scissors, were weighed

158 into individual $60 \mathrm{ml} \mathrm{screw-capped} \mathrm{polypropylene} \mathrm{centrifuge} \mathrm{tubes.} \mathrm{After} \mathrm{the} \mathrm{addition}$

159 of $40 \mathrm{ml}$ of extraction fluid, all tubes, including a control containing no solid material,

160 were capped and incubated in a shaking water bath set at $100 \mathrm{rpm}$ and at $40{ }^{\circ} \mathrm{C}$ for a

161 period of about seven days $(168 \mathrm{~h})$. At pre-determined time-intervals, $1 \mathrm{ml}$ aliquots of

162 extract were pipetted into individual Sterilin tubes where they were diluted to $5 \mathrm{ml}$

163 with $2 \% \mathrm{HNO}_{3}$ and stored at $4{ }^{\circ} \mathrm{C}$ and in the dark pending analysis.

164

165 2.5. Analysis of extracts

166 Elements detected directly in the rope samples by XRF (with the exception of $\mathrm{Cl}$ )

167 were determined in the PBET extracts by collision cell-inductively coupled plasma-

168 mass spectrometry (ICP-MS) using a Thermo X-series II (Thermoelemental,

169 Winsford UK) with a concentric glass nebuliser and conical spray chamber. The ICP

170 was calibrated externally using five mixed standards and five blanks prepared in $2 \%$

$171 \mathrm{HNO}_{3}$ and operated under conditions described elsewhere (Turner and Holmes, 2015).

172 Limits of detection, based on three standard deviations arising from blank

173 measurements, ranged from about $0.05 \mu \mathrm{g} \mathrm{L} \mathrm{L}^{-1}$ for $\mathrm{Pb}$ to about $10 \mu \mathrm{g} \mathrm{L}^{-1}$ for $\mathrm{Br}$ and $\mathrm{Fe}$. 


\section{Results}

176

177

178

179

180

181

182

183

184

185 yellow samples encountered on both beaches but black and white samples restricted to

\subsection{Sample characteristics}

In total, 153 samples of filamentous plastic litter were collected (100 from Whitsand and 53 from Constantine), a selection of which is illustrated in Figure 2. Sample length ranged from about 2 to $15 \mathrm{~cm}$ and sample thickness from about 0.1 to $20 \mathrm{~mm}$. Dry sample mass ranged from about $90 \mathrm{mg}$ to $6 \mathrm{~g}$, and the total mass of material collected was $167 \mathrm{~g}$ (126 $\mathrm{g}$ from Whitsand and $41 \mathrm{~g}$ from Constantine).

The majority of samples $(n=149)$ consisted of twisted or braided strands that exhibited various degrees of fraying at the ends and disintegration throughout but with little evidence of fouling. Braided samples were usually flat but occasionally rounded and lacked a distinct or hollow core; many of these samples were kinked, hockled and/or knotted. Other samples consisted of monofilament line that was entangled and, in one case, bundled and knotted. FTIR analysis revealed that the majority (> 90\%) of twisted and braided samples and two of the monofilament lines were polyethylene; remaining twisted and braided samples were polypropylene or a combination of polyethylene and polypropylene while remaining monofilament lines were polyamide.

Table 1 provides a classification of filamentous plastic litter by colour for both beaches. (Note that where braided samples were constructed of strands of two or more colours, the dominant colour was used for categorisation purposes.) Overall, green and blue were the principal colours on both a number and mass basis, with orange and Whitsand and a single red sample encountered at Constantine. Monofilament line was 
199 either green or orange, while all other green samples and the single red sample were

200 braided; remaining colours were distributed between both braided and twisted types of

201 filamentous litter.

\subsection{Elemental concentrations}

204 Also shown in Table 1 are summary statistics for each trace element on both beaches. 205 Among the elements analysed, $\mathrm{Hg}$ was never detected and $\mathrm{As}, \mathrm{Ba}, \mathrm{Bi}, \mathrm{Cd}, \mathrm{Ni}, \mathrm{Sb}, \mathrm{Se}$ 206 and Sn were detected in six cases or less; regarding the latter group, Ni was detected 207 only in samples from Constantine while remaining elements were detected only in 208 samples from Whitsand. Bromine, $\mathrm{Cr}$ and $\mathrm{Cu}$ were detected in more than half and $\mathrm{Pb}$ 209 and $\mathrm{Zn}$ in just under half of all samples. These elements were distributed across all 210 colour categories that contained multiple samples, but $\mathrm{Cu}$ was only detected in one 211 orange sample and $\mathrm{Br}$ exhibited limited occurrence in yellow and orange samples.

212 Median and maximum concentrations of $\mathrm{Cr}$ and $\mathrm{Pb}$ were considerably higher in the

213 orange category than in the remaining colours, and the highest individual

214 concentrations of $\mathrm{Cr}, \mathrm{Pb}$ and $\mathrm{Br}$ and the only case in which $\mathrm{Cd}$ and $\mathrm{Se}$ were detected 215 also occurred among the orange samples.

\subsection{PBET results}

218 There were only four cases in which extractable trace elements were detectable

219 throughout the PBETs; namely, $\mathrm{Br}$ in an orange polyethylene braided fragment 220 containing the highest total $\mathrm{Br}$ content, $\mathrm{Cd}$ in a bundle of orange, polyethylene strands 221 knotted together and representing the only sample in which the metal was detectable 222 by XRF (see below and Figure 3), and $\mathrm{Cr}$ and $\mathrm{Pb}$ in an orange polyethylene twisted 223 fragment containing the highest contents of both elements. Extracted concentrations, 
224 shown in Figure 4, exhibit a biphasic distribution consisting of a period of relatively

225 rapid increase over the first few hours followed by a more protracted period of slower

226 release. With no evidence of equilibrium being approached, data were fitted

227 empirically with an equation of the following form (Turner and Lau, 2016):

228

$229 \quad[\mathrm{X}(t)]=k t^{1 / b}$

231 where $t$ and $[\mathrm{X}(t)]$ represent time and w/v time-dependent extractable elemental 232 concentration, respectively, and $k$ and $b$ are constants. Concentrations and constants

233 defining the kinetics of elemental mobilisation and derived from best-fit power

234 equations to the timed data are given in Table 2 . Here, $\left[\mathrm{X}_{\mathrm{T}}\right]$ is the total, w/w

235 concentration as returned by the $\mathrm{XRF},\left[\mathrm{X}_{\max }\right]$ is the maximum w/w concentration at

236 the termination of the PBET, and $\mathrm{X}_{\max }$ relative to $\mathrm{X}_{\mathrm{T}}$ represents the avian

237 bioaccessibility after a period of seven days, with percentages ranging from $<0.5$ for

$238 \mathrm{Cd}, \mathrm{Cr}$ and $\mathrm{Pb}$ to about 7 for $\mathrm{Br}$.

\section{Discussion}

241 Although a few samples exhibited an appearance consistent with packaging or bale

242 twine, it is suspected that the majority of filamentous plastic debris sampled in the

243 present study originated from commercial fishing. Specifically, pieces of line or

244 braided or twisted rope are generated during the damage, repair and abandonment of

245 netting, and protective threads of dolly rope (chafer) are fractured as trawl nets are

246 dragged along the seabed (Murray and Cowan, 2011). With samples being mostly

247 constructed of polyethylene and polypropylene, whose densities ( 0.92 to $\left.0.96 \mathrm{~g} \mathrm{~cm}^{-3}\right)$

248 are less than that of sea water (1.02 to $\left.1.03 \mathrm{~g} \mathrm{~cm}^{-3}\right)$, and devoid of significant fouling, 
this material is readily washed up on beaches. By the same reasoning, lack of samples retrieved that were composed of polyester, another common polymer used in fishing

251 nets, can be explained by its higher density (about $1.4 \mathrm{~g} \mathrm{~cm}^{-3}$ ) and propensity to sink

252 when lost or discarded at sea.

254 The presence of trace elements in the samples is the result of additives or 255 polymerisation catalyst residues in the plastic matrix. Depending on the application of 256 the plastic, organic and inorganic additives may serve as fillers, pigments for colour, 257 thermal stabilisers, UV-light stabilisers, flame retardants or antimicrobials (Ranta258 Korpi et al., 2014). Regarding fishing rope and line, UV resistance is a particular 259 requirement and specific colours may be needed for visibility, contrast and visual 260 stimulus. Of concern from an environmental perspective is the addition of trace 261 elements that are intrinsically hazardous (e.g. $\mathrm{Cd}, \mathrm{Cr}$ and $\mathrm{Pb}$ ) or that are a component 262 of hazardous substances (e.g. Br) to achieve these requirements. Hazardous elements 263 were most abundant in or restricted to filamentous material that was orange, a colour 264 that is often employed to minimise horizontal contrast between netting and a grey265 green water background (Wardle, 1986).

267 Where both $\mathrm{Cr}$ and $\mathrm{Pb}$ were detected in orange and yellow samples (that were all 268 polyethylene), concentrations of the metals were significantly correlated (Figure 5), 269 with all data points lying close to or below the slope defining the mass ratio of $\mathrm{Pb}$ to $270 \mathrm{Cr}$ in the pigment, lead chromate $\left(\mathrm{PbCrO}_{4}\right)$. Lead chromate itself is bright yellow but 271 mixing with lead molybdate and lead sulphate produces a more light- and acid272 resistant orange pigment (Maier and Calafut, 1998). While chromates have been used 273 in many polymers and in a variety of applications for colour, brightness, opacity and 
274 fastness, concerns about the toxicities and health impacts of $\mathrm{Pb}$ and hexavalent $\mathrm{Cr}$

275 have resulted in these compounds being restricted or phased out by the paint and

276 plastic industries. Under the EU's REACH Regulation (EC 1907/2006 on the

277 Registration, Evaluation, Authorisation and Restriction of Chemicals), for example,

278 lead chromate has recently been banned following its identification as a substance of

279 very high concern (SVHC) (ECHA, 2009). This classification requires suppliers of

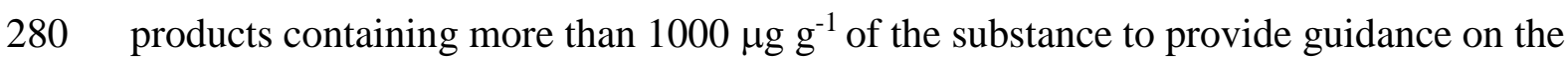

281 safe use and disposal of the material. Because lead chromate appears to be, or to have

282 been, commonly employed in fishing nets and line, and at concentrations often well in

283 excess of $1000 \mu \mathrm{g} \mathrm{g}^{-1}$, such guidance would also be applicable to the fishing industry.

285 Cadmium was detected in one sample that, visually, was distinctly different to all

286 other samples collected. Specifically, it consisted of about 15 bright orange

287 polyethylene threads, of about $7 \mathrm{~cm}$ in length and $1 \mathrm{~mm}$ in diameter, that had not been

288 intertwined but tied together as a bundle (Figure 3). It is suspected that this sample is

289 a fragment of protective dolly rope that had been torn off on the sea bed or cast

290 overboard during cutting or repair. The presence of Se in this sample suggests that the

291 pigment employed for colour is cadmium sulphoselenide, a brilliant orange solid

292 solution of CdS and CdSe. Although no hazards have been classified by the European

293 Chemicals Agency for the pigment itself, compounds of both Cd and Se are highly

294 toxic. According to the REACH Regulation, Cd is only permitted for use in plastics at

295 concentrations below $100 \mu \mathrm{g} \mathrm{g}^{-1}$ with the exception of articles constructed for safety

296 reasons and where environmental or operating conditions are extreme or colour

297 fastness and lifespan are critical (ECHA, 2012). 
299 There are very few Br-containing colour pigments used in plastics, the principal one 300 being based on halogenated copper phthalocynanine. Here, the ratio of $\mathrm{Cl}$ to $\mathrm{Br}$ is 301 varied to effect different shades of green (Lewis, 2000), with the maximum Br content 302 of the pigment being about $60 \%$ by weight and typical $\mathrm{Br}$ residue concentrations in 303 plastics ranging from 60 to $3000 \mu \mathrm{g} \mathrm{g}^{-1}$ (Ranta-Korpi et al., 2014). Consistent with 304 these characteristics, $\mathrm{Br}$ was most frequently encountered in green ropes at 305 concentrations up to about $80 \mu \mathrm{g} \mathrm{g}^{-1}$, and in all but two of these samples $\mathrm{Cu}$ was 306 detectable and at concentrations up to about $700 \mu \mathrm{g} \mathrm{g}^{-1}$. A more important use of $\mathrm{Br}$ in 307 polymers, however, is as a component of various aromatic and aliphatic brominated 308 flame retardants, such as polybrominated diphenyl ethers, polybrominated biphenyl, 309 tetrabromobisphenol A and hexabromocyclododecane. Flame retardants may be 310 additive or reactive and occur in plastics at concentrations of up to a few per cent by 311 weight (Leslie et al., 2016). Many of the more toxic retardants have been classified as 312 SVHC under the REACH classification and as such have been restricted, phased out 313 or banned. Neither FP-XRF nor FTIR are able to directly identify or discriminate 314 brominated species in plastics unless molecular concentrations exceed a few percent.

315 However, the three rope samples (one orange and two white) containing $\mathrm{Br}$ in excess 316 of $500 \mu \mathrm{g} \mathrm{g}^{-1}$ but with no detectable $\mathrm{Cu}$ and, in one case, the highest measured 317 concentration of Sb (a component of the flame retardant synergist, antimony trioxide), 318 are suspected to have been impregnated with brominated retardants.

320 Clearly, the impacts of toxic elements in filamentous plastic litter on wildlife depend 321 on the scope for material to be ingested and the propensity of compounds to migrate 322 from the polymeric matrix. Ingestion of synthetic fibres arising from the deterioration, 323 degradation or abrasion of debris is known to occur in birds (Tanaka et al., 2013), 
turtles (De Carvalho-Souza et al., 2016), invertebrates (Mathalon and Hill, 2014), crustaceans (Watts et al., 2015) and fish (Dantas et al., 2012), and there is evidence that orange material is preferentially ingested over other colours. For example, De Witte et al. (2014) observed a high proportion of orange fibres in the bodies of mussels from quayside mussels, while photographs of plastics retrieved from the stomachs of the short-tailed shearwater presented in Tanaka et al. (2013) illustrate filamentous debris that is orange. Although not empirically tested, it has been suggested that such colours could be popular due to food/prey resemblance (as, for example, fish eggs, larvae and zooplankton) (Kawamura et al., 2010; De Witte et al., 2014). Once ingested, filamentous material tends to remain in the digestive tract for longer periods than other plastic debris, and in particular in the less acidic gastric environments of small invertebrates, crustaceans and fish. This is because of both the requirement of individual strands having to orientate 'end-on' to pass through the gut and an increase in the effective size of strands through filament 'balling' (Murray and Cowie, 2011).

Regarding elemental mobilisation, lead chromate is sparingly soluble $\left(K \mathrm{sp}=1.8 \times 10^{-}\right.$ ${ }^{14}$ at $25^{\circ} \mathrm{C}$ ) but dissolution is facilitated in saline solutions, with $\mathrm{Pb}$ appearing to leach more rapidly than $\mathrm{Cr}$ (White et al., 2014). Differential leaching under saline conditions may explain why many weathered, orange and yellow filamentous fragments retrieved from beaches have $\mathrm{Pb}$ to $\mathrm{Cr}$ ratios below the value defining pure lead chromate (Figure 5). With respect to mobilisation under the simulated acidic avian gastric conditions, we estimate seven-day bioaccessibilities of about $0.4 \%$ and $0.2 \%$ for $\mathrm{Cr}$ and $\mathrm{Pb}$, respectively (Table 2 ). 
349 Although both cadmium selenide and cadmium sulphide are negligibly soluble $(K \mathrm{sp}=$ $6.3 \times 10^{-36}$ and $8.0 \times 10^{-28}$ at $25^{\circ} \mathrm{C}$, respectively), $\mathrm{Cd}$, but not Se, was detected

351 throughout the time-course of the PBET, with a bioaccessibility relative to total Cd of 352 about $0.3 \%$ at the end of the experiment (Table 2). In contrast, the bioaccessibility of $353 \mathrm{Br}$ at the end of the corresponding time-course was about 7\%, from which we may 354 infer that brominated flame retardants in this particular polyethylene were physically 355 added to the polymer rather than being chemically bonded to it.

While the physical hazards to marine life arising from filamentous plastic, ranging

358 from microscopic fibres to large fragments of fishing nets, are well-documented

359 (Jacobsen et al., 2010; Denuncio et al., 2011; Benemann et al., 2016; Watts et al., 360 2014), this study has highlighted the potentially hazardous nature of such waste from

361 a chemical perspective. Of particular concern is the occurrence of substances that 362 have been restricted or banned in orange-yellow fragments derived from fishing 363 activities. That these substances have been employed in (an albeit) decreasing range 364 of plastic products over the past few decades (Hansen et al., 2010) suggests material 365 for netting and rope is sourced from a variety of suppliers that are not necessarily 366 tailored to the fishing industry. Among the most hazardous elements considered, $\mathrm{Pb}$ 367 exhibited the highest abundance overall but $\mathrm{Br}$ exhibited the greatest avian 368 bioaccessibility. This observation is consistent with the propensity of sea birds to 369 accumulate congeners of brominated flame retardants that are not present in natural 370 prey (pelagic fish) but in plastic fragments that have been ingested (Tanaka et al., 371 2013). Although the avian bioaccessibilities of $\mathrm{Cd}, \mathrm{Cr}$ and $\mathrm{Pb}$ are relatively low, it 372 must be borne in mind that kinetic profiles indicate continuous release from 373 filamentous plastic and that synthetic material may be trapped in the digestive system 
374 of some seabirds for periods of months or even years (Laist, 1987; Avery-Gomm et 375 al., 2012).

\section{Acknowledgements}

378 Mr Kev Solman, Mr Andy Arnold, Mr Oliver Leach, Mr Andrew Tonkin, Dr Dave

379 Harwood and Dr Andrew Fisher (UoP) are thanked for technical assistance and advice 380 during the study. This work was funded by a UoP Marine Institute HEIF V grant.

\section{References}

Avery-Gomm, S, O'Hara, P.D., Kleine, L., Bowes, V., Wilson, L.K., Barry, K.L., 2012. Northern fulmars as biological monitors of trends of plastic pollution in the eastern North Pacific. Marine Pollution Bulletin 64, 1776-1781.

Benemann, V.R.F., Krueger, L., Valls, F.C.L., Petry, M.V., 2016. Evidence of an unreported negative effect of fisheries discards on seabirds: death by choking on the Atlantic Midshipman, Porichthys porosissimus, in southern Brazil. EMU 116, 48-51.

Dantas, D.V., Barletta, M., da Costa, M.F., 2012. The seasonal and spatial patterns of ingestion of polyfilament nylon fragments by estuarine drums (Sciaenidae). Environmental Science and Pollution Research International 19, 600-606. gardens: A report on failures of recognition by green turtles and their conservation implications. Marine Pollution Bulletin 105, 98-101. 
399 De Witte, B., Devriese, L., Bekaert, S., Hoffman, G., Vandermeersch, K., Cooreman,

400 K., Robbens, J., 2014. Quality assessment of the blue mussel (Mytilus edulis):

401 Comparison between commercial and wild types. Marine Pollution Bulletin 85, 146-

402155.

403

404 Denuncio, P., Bastida, R., Dassis, M., Giardino, G., Gerpe, M., Rodriguez, D., 2011.

405 Plastic ingestion in Franciscana dolphins, Pontoporia blainvillei (Gervais and

406 d'Orbigny, 1844), from Argentina. Marine Pollution Bulletin 62, 1836-1841.

407

408 Devriese, L.I., van der Meulen, M.D., Maes, T., Bekaert, K., Paul-Pont, I., Frere, L.,

409 Robbens, J., Vethaak, A.D., 2015. Microplastic contamination in brown shrimp

410 (Crangon crangon, Linnaeus 1758) from coastal waters of the Southern North Sea

411 and Channel area. Marine Pollution Bulletin 98, 179-187.

412

413 ECHA, 2009. Member state committee support document for identification of

414 lead sulfochromate yellow (CI Pigment Yellow 34) as a substance of very high

415 concern because of its CMR properties. European Chemicals Agency, Helsinki.

416

417 ECHA, 2012. Annex XVII to Reach - Restrictions on the manufacture, placing on the

418 market and use of certain dangerous substances, mixtures and articles; Entry 23:

419 Cadmium. European Chemicals Agency, Helsinki.

421 Gilardi, K.V.K., Carlson-Bremer, D., June, J.A., Antonelis, K., Broadhurst, G.,

422 Cowan, T., 2010. Marine species mortality in derelict fishing nets in Puget Sound,

423 WA and the cost/benefits of derelict net removal. Marine Pollution Bulletin 60, 376$424 \quad 382$. 
426 Hansen, E., Nilsson, N.H., Lithner, D., Lassen, C., 2010. Hazardous substances in 427 plastic materials, COWI and the Danish Technological Institute on behalf of The 428 Norwegian Climate and Pollution Agency, Oslo, 150 pp.

430 Jacobsen, J.K., Massey, L., Gulland, F., 2010. Fatal ingestion of floating net debris by 431 two sperm whales (Physeter macrocephalus). Marine Pollution Bulletin 60, 765-767. 432

433 Kawamura, G., Kasedou, T., Tamiya, T., Watanabe, A., 2010. Colour preferences of 434 five marine fishes: Bias for natural and yellow-dyed krill in laboratory tanks, sea 435 cages and an earthen pond. Marine and Freshwater Behavioural Physiology 43, 169436182.

Laist, D.W., 1987. Overview of the biological effects of lost and discarded plastic 439 debris in the marine environment. Marine Pollution Bulletin 18, 319-326.

441 Lawson, T.J., Wilcox, C. Johns, K., Dann, P., Hardesty, B.D., 2015. Characteristics of 442 marine debris that entangle Australian fur seals (Arctocephalus pusillus doriferus) in 443 southern Australia. Marine Pollution Bulletin 98, 354-357.

445 Leslie, H.A., Leonards, P.E.G., Brandsma, S.H., de Boer, J., Jonkers, N., 2016.

446 Propelling plastics into the circular economy — weeding out the toxics first.

447 Environment International 94, 230-234. 
449 Lewis, P.J., 2000. Coloured organic pigments. In: Applied Polymer Science $21^{\text {st }}$

450 Century. Ed. C.D. Craver and C.E. Carraher, Elsevier, Oxford, pp. 493-526.

452 McIntosh, R.R., Kirkwood, R., Sutherland, D.R., Dann, P., 2015. Drivers and annual

453 estimates of marine wildlife entanglement rates: A long-term case study with

454 Australian fur seals. Marine Pollution Bulletin 101, 716-725.

455

456 Maier, C., Calafut, T., 1998. Polypropylene: The Definitive User's Guide and

457 Databook. William Andrew, Norwich NY, 431pp.

458

459 Mathalon, A., Hill, P., 2014. Microplastic fibers in the intertidal ecosystem

460 surrounding Halifax Harbor, Nova Scotia. Marine Pollution Bulletin 81, 69-79.

461

462 Nadal, M.A., Alomar, C., Deudero, S., Deudero, S., 2016. High levels of microplastic

463 ingestion by the semipelagic fish bogue Boops boops (L.) around the Balearic Islands.

464 Environmental Pollution 214, 517-523.

465

466 Murray, F., Cowie, P.R., 2011. Plastic contamination in the decapod crustacean

467 Nephrops norvegicus (Linnaeus, 1758). Marine Pollution Bulletin 62, 1207-1217.

468

469 OSPAR Commission, 2010. Guideline for monitoring marine litter on the beaches in

470 the OSPAR maritime area. OSPAR Commission, London, 84pp. 
473 elements in plastics and rubbers. VTT Technical Research Centre of Finland, Espoo, 474 Finland, 131pp.

475

476 Tanaka, K., Takada, H., Yamashita, R., Mizukawa, K., Fukuwaka, M., Watanuki, Y., 477 2013. Accumulation of plastic-derived chemicals in tissues of seabirds ingesting 478 marine plastics. Marine Pollution Bulletin 69, 219-222.

479

480 Turner, A., 2016. Hazardous metals, metalloids and other elements in marine litter.

481 Marine Pollution Bulletin 111, 136-142.

482

483 Turner, A., Holmes, L., 2015. Adsorption of trace metals by microplastic pellets in 484 fresh water. Environmental Chemistry 12, 600-610.

485

Turner, A., Lau, K., 2016. Elemental concentrations and bioaccessibilities in beached 487 plastic foam litter, with particular reference to lead in polyurethane. Marine Pollution 488 Bulletin 112, 265-270.

489

490 Turner, A., Solman, K.R., 2016. Analysis of the elemental composition of marine

491 litter by field-portable-XRF. Talanta 159, 262-271.

492

493 Verlis, K.M., Campbell, M.L., Wilson, S.P., 2013. Ingestion of marine debris plastic 494 by the wedge-tailed shearwater Ardenna pacifica in the Great Barrier Reef, Australia. 495 Marine Pollution Bulletin 72, 244-249. 
Votier, S.C., Archibald, K., Morgan, G., Morgan, L., 2011. The use of plastic debris as nesting material by a colonial seabird and associated entanglement mortality.

499 Marine Pollution Bulletin 62, 168-172.

501 Welden, N.A.C., Cowie, P.R., 2016. Long-term microplastic retention causes reduced 502 body condition in the langoustine, Nephrops norvegicus. Environmental Pollution $503218,895-900$.

505 White, K., Detherage, T., Verellen, M., Tully, J., Krekeler, M.P.S., 2014. An 506 investigation of lead chromate (crocoite- $\mathrm{PbCrO}_{4}$ ) and other inorganic pigments in 507 aged traffic paint samples from Hamilton, Ohio: implications for lead in the 508 environment. Environmental Earth Science 71, 3517-3528.

510 Wardle, C.S. 1986. Fish behaviour and fishing gear. In: The Behaviour of Teleost 511 fishes. Ed. Pitcher, T.J., Croom Helm, London, pp 463-495.

513 Watts, A.J.R., Urbina, M.A., Corr, S., Lewis, C., Galloway, T., 2015. Ingestion of 514 plastic microfibers by the crab Carcinus maenas and its effect on food consumption 515 and energy balance. Environmental Science and Technology 49, 14597-14604. 
521 Table 1: Summary statistics for the concentrations of trace elements $\left(\mu \mathrm{g} \mathrm{g}^{-1}\right)$ among the different

522 colours of beached filamentous plastic litter sampled from Whitsand and Constantine.

\begin{tabular}{|c|c|c|c|c|c|c|c|c|c|c|c|c|c|c|c|}
\hline beach & & As & $\mathrm{Ba}$ & $\mathrm{Bi}$ & $\mathrm{Br}$ & $\mathrm{Cd}$ & $\mathrm{Cr}$ & $\mathrm{Cu}$ & $\mathrm{Fe}$ & $\mathrm{Ni}$ & $\mathrm{Pb}$ & $\mathrm{Sb}$ & Se & Sn & $\mathrm{Zn}$ \\
\hline \multicolumn{16}{|l|}{ Whitsand } \\
\hline \multirow[t]{4}{*}{ black $(n=9)$} & median & & & & 19.2 & & 89.9 & 128 & 998 & & 83.5 & 61.4 & & & 76.6 \\
\hline & $\min$. & & & & 5.5 & & 36.1 & 11.6 & 267 & & 11.9 & & & & 29.5 \\
\hline & $\max$. & & & & 365 & & 314 & 195 & 15,400 & & 1010 & & & & 163 \\
\hline & $n$ & & & & 5 & & 5 & 4 & 9 & & 7 & 1 & & & 6 \\
\hline \multirow[t]{4}{*}{ blue $(n=25)$} & median & & & 11.3 & 20.1 & & 122 & 119 & 1620 & & 90.8 & 245 & & & 37.7 \\
\hline & $\min$. & & & 10.4 & 3.8 & & 23.1 & 35.4 & 338 & & 7.6 & & & & 10.9 \\
\hline & $\max$. & & & 12.2 & 72.1 & & 591 & 367 & 7790 & & 834 & & & & 588 \\
\hline & $n$ & & & 2 & 13 & & 18 & 18 & 25 & & 8 & 1 & & & 5 \\
\hline \multirow[t]{4}{*}{ green $(n=39)$} & median & 4.4 & 149 & 6.5 & 18.9 & & 44.4 & 67.8 & 1360 & & 17.5 & 99.0 & & 20.0 & 40.2 \\
\hline & $\min$. & & & & 5.0 & & 23.2 & 22.0 & 242 & & 2.8 & & & & 16.6 \\
\hline & $\max$. & & & & 63.7 & & 219 & 671 & 8090 & & 376 & & & & 341 \\
\hline & $n$ & 1 & 1 & 1 & 28 & & 19 & 32 & 39 & & 17 & 1 & & 1 & 16 \\
\hline \multirow[t]{4}{*}{ orange $(n=8)$} & median & & & 23.2 & 21.4 & 1460 & 420 & & 713 & & 806 & 75.4 & 240 & 23.9 & 33.8 \\
\hline & $\min$. & & & & 11.2 & & 160 & & 92.5 & & 336 & & & & 18.4 \\
\hline & $\max$. & & & & 2420 & & 786 & & 4900 & & 2570 & & & & 57.1 \\
\hline & $n$ & & & 1 & 3 & 1 & 7 & & 8 & & 7 & 1 & 1 & 1 & 5 \\
\hline \multirow[t]{4}{*}{ white $(n=17)$} & median & & 1340 & & 74.5 & & 73.4 & 51.7 & 4080 & & 35.1 & 795 & & 183 & 52.2 \\
\hline & $\min$. & & & & 5.3 & & 24.9 & 37.9 & 789 & & 8.0 & 276 & & & 28.5 \\
\hline & $\max$. & & & & 681 & & 431 & 60.9 & 18,900 & & 348 & 1310 & & & 69.5 \\
\hline & $n$ & & 1 & & 12 & & 12 & 3 & 17 & & 8 & 2 & & 1 & 7 \\
\hline \multirow[t]{4}{*}{ yellow $(n=2)$} & median & & & & & & 157 & 235 & 658 & & 653 & & & & 24.7 \\
\hline & $\min$. & & & & & & 31.9 & & 607 & & & & & & \\
\hline & max. & & & & & & 282 & & 709 & & & & & & \\
\hline & $n$ & & & & & & 2 & 1 & 2 & & 1 & & & & 1 \\
\hline \multirow[t]{4}{*}{ all $(n=100)$} & median & 4.4 & 744 & 7.1 & 21.4 & 1460 & 79.1 & 76.7 & 1521 & & 62.6 & 172 & 240 & 23.9 & 46.0 \\
\hline & $\min$. & & 149 & 6.5 & 3.9 & & 23.1 & 11.6 & 92.5 & & 2.8 & 61.4 & & 20.0 & 10.9 \\
\hline & $\max$. & & 1340 & 23.2 & 2420 & & 786 & 671 & 18,900 & & 2570 & 1310 & & 183 & 588 \\
\hline & $n$ & 1 & 2 & 4 & 61 & 1 & 63 & 58 & 100 & & 48 & 6 & 1 & 3 & 40 \\
\hline \multicolumn{16}{|l|}{ Constantine } \\
\hline \multirow[t]{4}{*}{ blue $(n=7)$} & median & & & & 30.2 & & 69.5 & 85.6 & 2630 & & 123 & & & & 34.2 \\
\hline & $\min$. & & & & 17.4 & & 27.8 & 30.7 & 513 & & & & & & 29.7 \\
\hline & $\max$. & & & & 90.9 & & 109 & 808 & 3820 & & & & & & 74.5 \\
\hline & $n$ & & & & 3 & & 4 & 7 & 7 & & 1 & & & & 3 \\
\hline \multirow[t]{4}{*}{ green $(n=26)$} & median & 16.9 & & & 18.4 & & 35.9 & 58.7 & 1190 & 735 & 34.0 & & & & 21.6 \\
\hline & $\min$. & & & & 8.7 & & 25.3 & 26.8 & 155 & & 26.9 & & & & 14.6 \\
\hline & $\max$. & & & & 82.3 & & 69.8 & 538 & 29,200 & & 314 & & & & 35.2 \\
\hline & $n$ & & & & 12 & & 8 & 24 & 26 & 1 & 7 & & & & 10 \\
\hline \multirow[t]{4}{*}{ orange $(n=8)$} & median & & & & 14.8 & & 530 & 91 & 939 & 37.2 & 1570 & & & & 36.4 \\
\hline & $\min$. & & & & & & 71.8 & & 465 & & 216 & & & & 22.9 \\
\hline & $\max$. & & & & & & 909 & & 1560 & & 3770 & & & & 47.5 \\
\hline & $n$ & & & & 1 & & 5 & 1 & 8 & 1 & 5 & & & & 4 \\
\hline \multirow[t]{2}{*}{$\operatorname{red}(n=1)$} & median & & & & 22.8 & & 56.3 & & 3690 & & & & & & 145 \\
\hline & $n$ & & & & 1 & & 1 & & 1 & & & & & & 1 \\
\hline \multirow[t]{4}{*}{ yellow $(n=11)$} & median & & & & 21.1 & & 318 & 67.7 & 925 & & 203 & & & & 20.1 \\
\hline & $\min$. & & & & 15.2 & & 25.7 & 43.5 & 278 & & 72.9 & & & & 19.0 \\
\hline & $\max$. & & & & 27.1 & & 391 & 362 & 2110 & & 838 & & & & 66.2 \\
\hline & $n$ & & & & 2 & & 5 & 6 & 11 & & 8 & & & & 3 \\
\hline \multirow[t]{4}{*}{ all $(n=53)$} & median & 16.9 & & & 19.6 & & 56.3 & 71.2 & 1160 & 386 & 182 & & & & 26.0 \\
\hline & $\min$. & & & & 8.7 & & 25.3 & 26.8 & 155 & 37.2 & 26.9 & & & & 14.6 \\
\hline & $\max$. & & & & 90.9 & & 909 & 808 & 29,200 & 735 & 3770 & & & & 145 \\
\hline & $n$ & 1 & & & 19 & & 23 & 38 & 53 & 2 & 21 & & & & 21 \\
\hline
\end{tabular}


524 Table 2: Constants and concentrations defining the mobilisation of $\mathrm{Br}, \mathrm{Cd}, \mathrm{Cr}$ and $\mathrm{Pb}$

525 from three samples of orange, filamentous polyethylene $(\mathrm{W}=$ Whitsand; $\mathrm{C}=$

526 Constantine) whose kinetic profiles are illustrated in Figure 4. Note that an

527 explanation of terms is given in the text.

\begin{tabular}{ccccccccc}
\hline & sample & $\mathrm{X}$ & {$\left[\mathrm{X}_{\mathrm{T}}\right], \mu \mathrm{g} \mathrm{g}^{-1}$} & {$\left[\mathrm{X}_{\mathrm{max}}\right], \mu \mathrm{g} \mathrm{g}{ }^{-1}$} & {$\left[\mathrm{X}_{\mathrm{max}}\right] /\left[\mathrm{X}_{\mathrm{T}}\right], \%$} & $k, \mu \mathrm{L} \mathrm{L}^{-1} \mathrm{~h}^{-1 / b}$ & $b$ & $r^{2}$ \\
\cline { 2 - 9 } & W100 & $\mathrm{Br}$ & 2420 & 168 & 6.94 & 18.2 & 2.04 & 0.804 \\
& W86 & $\mathrm{Cd}$ & 1460 & 3.94 & 0.27 & 0.899 & 3.69 & 0.948 \\
& $\mathrm{C} 51$ & $\mathrm{Cr}$ & 909 & 3.28 & 0.36 & 9.17 & 14.6 & 0.276 \\
& $\mathrm{C} 51$ & $\mathrm{~Pb}$ & 3770 & 8.40 & 0.22 & 13.7 & 6.17 & 0.813 \\
\hline
\end{tabular}

529

530

531 
532 Figure 1: Sampling locations for the filamentous plastic litter analysed in the present 533 study.

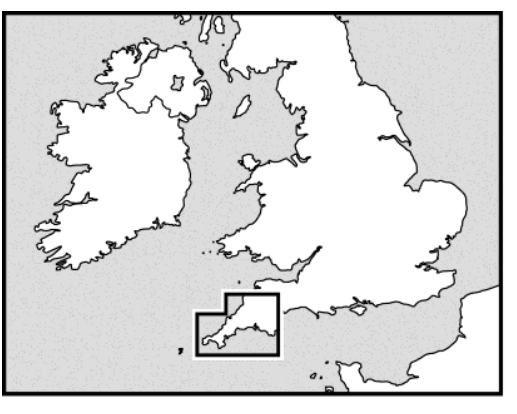

534

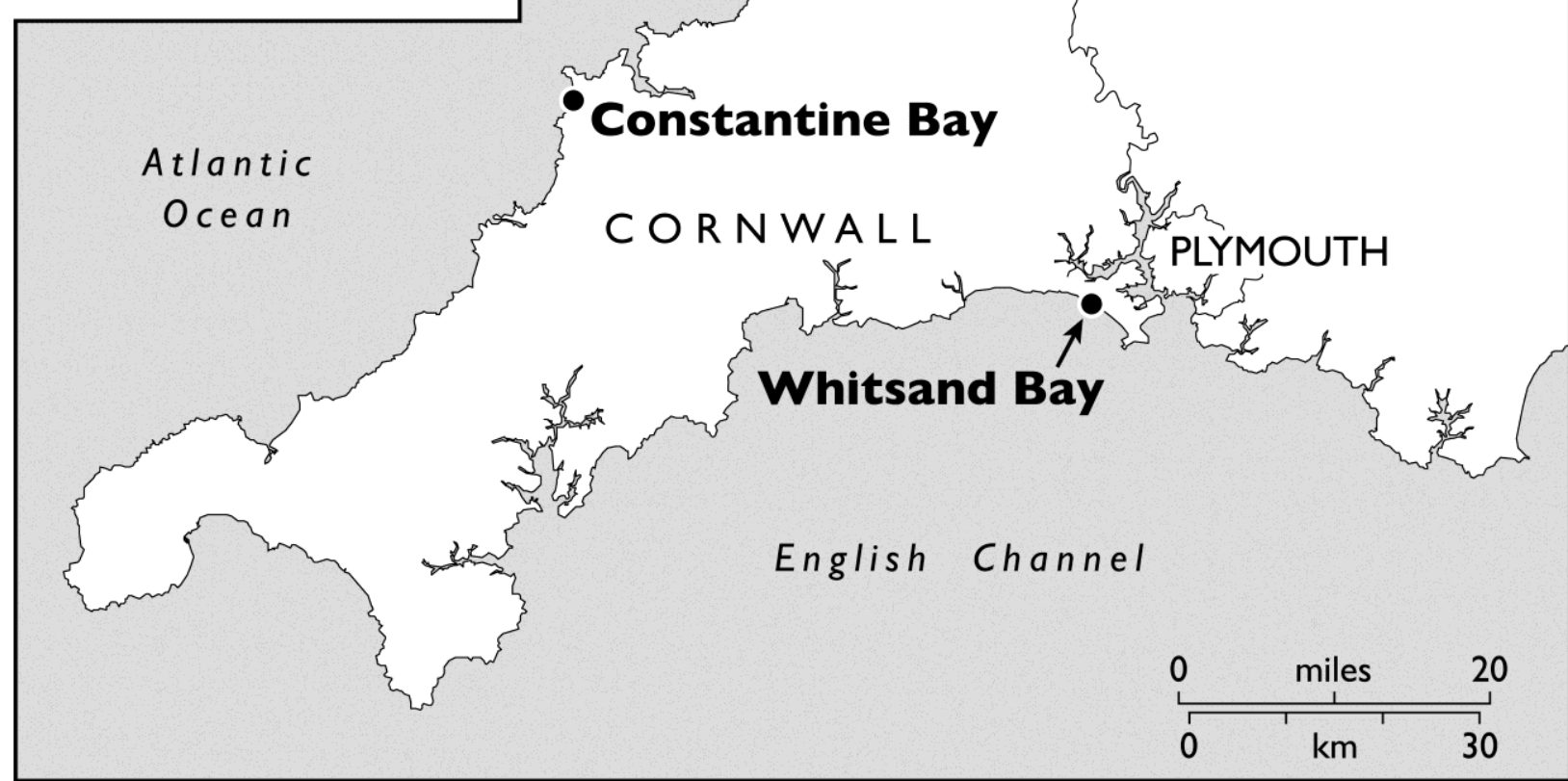


536 Figure 2: A selection of filamentous plastic samples collected in the present study.

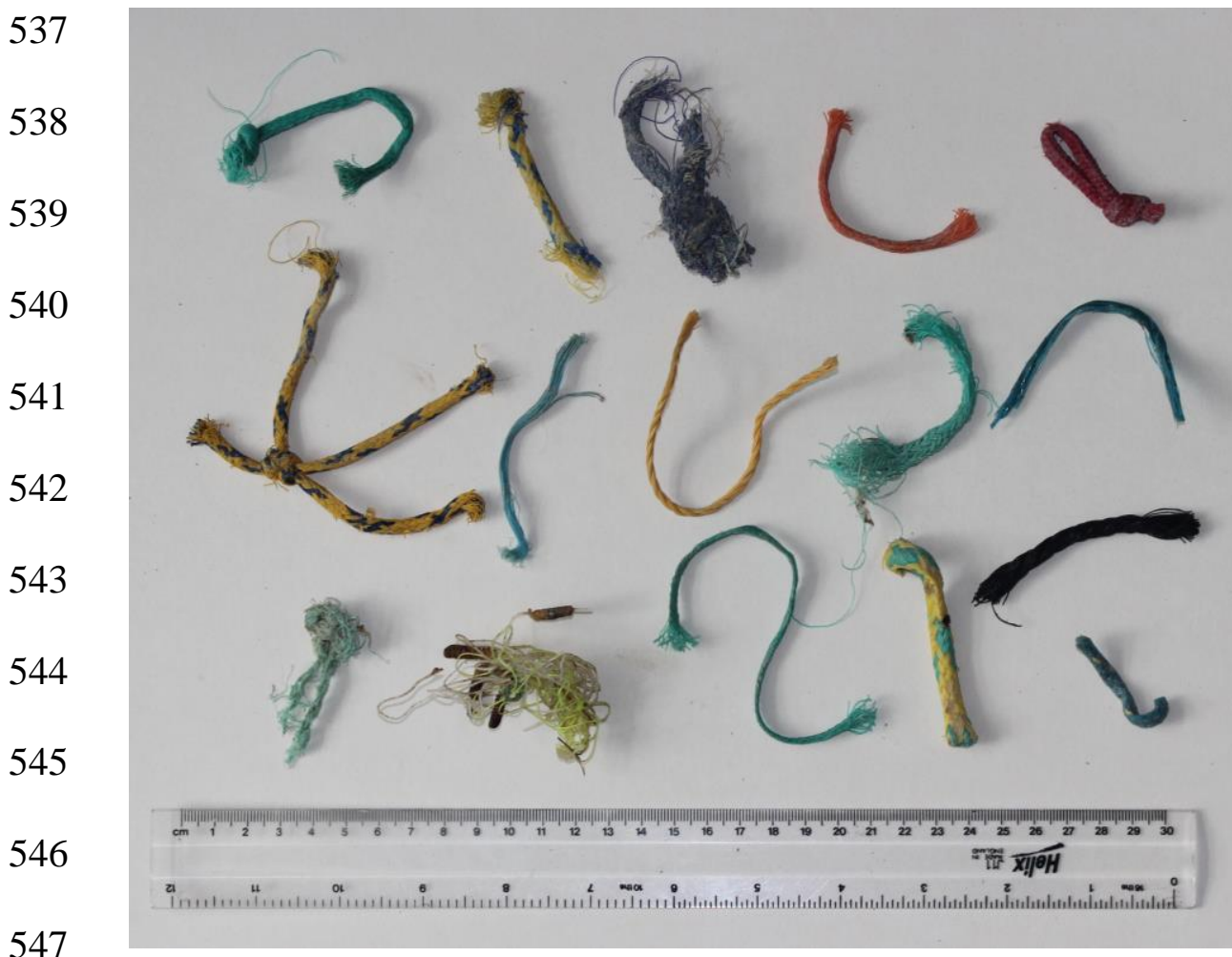

548

549 Figure 3: Orange polyethylene strands of approximately $7 \mathrm{~cm}$ in length that had been

550 knotted together and in which Cd and Se were detected (sample W86).

551

552

553

554

555

556

557

558

559

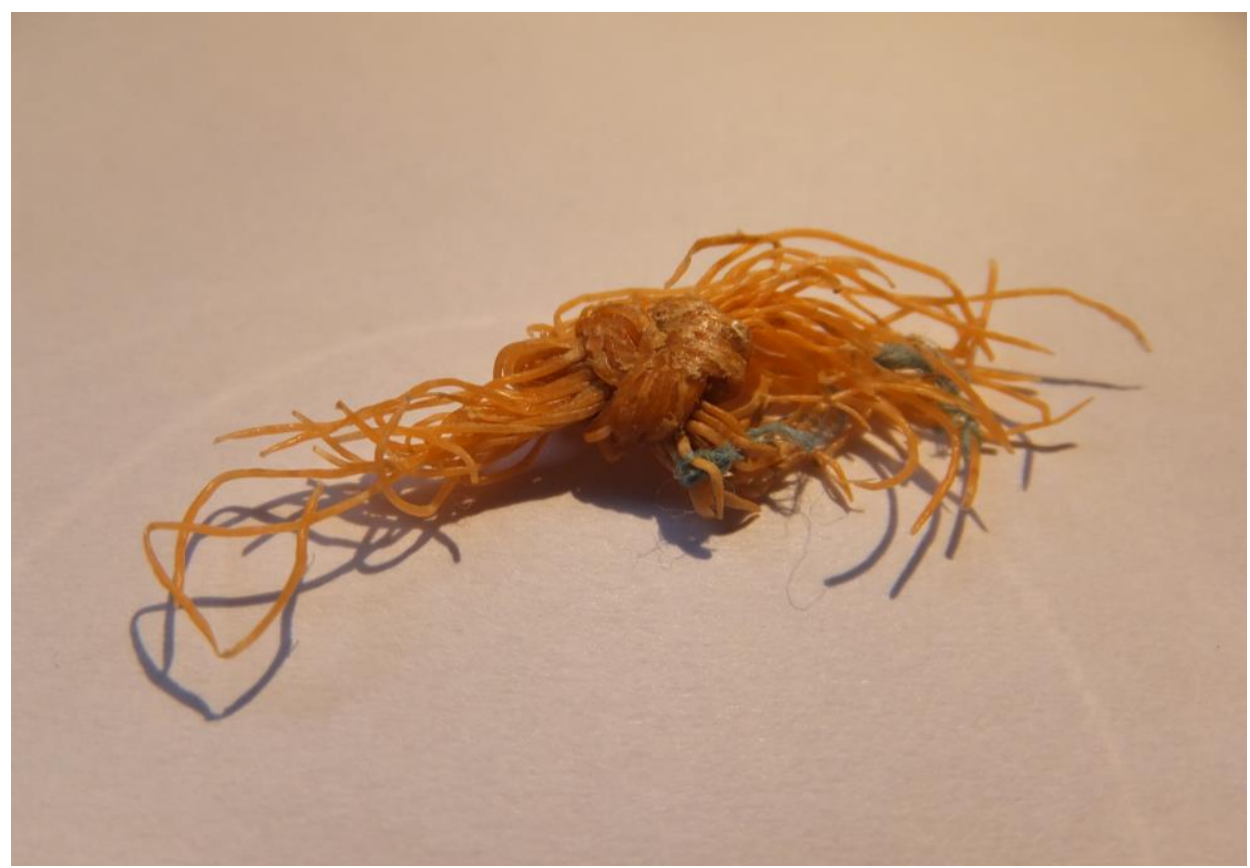


561 Figure 4: Kinetic profiles for the mobilisation of $\mathrm{Br}, \mathrm{Cd}, \mathrm{Cr}$ and $\mathrm{Pb}$ from three

562 samples of orange, filamentous polyethylene ( $\mathrm{W}=$ Whitsand; $\mathrm{C}=$ Constantine $)$ by the

563 avian PBET. Annotated are best-fits to the data according to equation 1. Constants

564 and concentrations (in $\mu \mathrm{g} \mathrm{g}^{-1}$ ) defining the samples and profiles are given in Table 2.
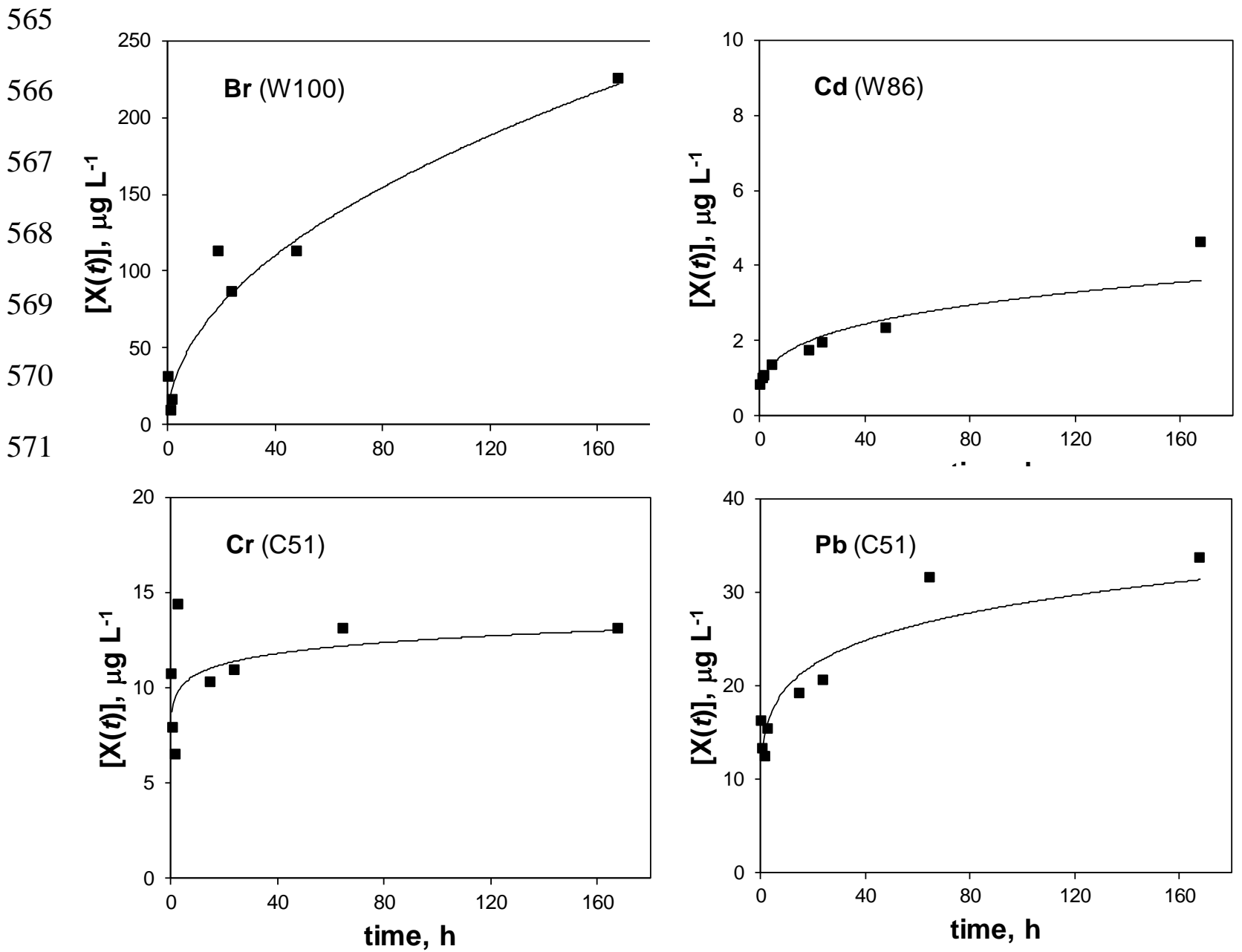
572 Figure 5: Concentration of $\mathrm{Pb}$ versus concentration of $\mathrm{Cr}$ in the orange (filled) and

573 yellow (open) samples from Whitsand (triangles) and Constantine (squares). The solid

574 line represents the ratio of $\mathrm{Pb}$ to $\mathrm{Cr}$ in lead chromate (3.98).

575

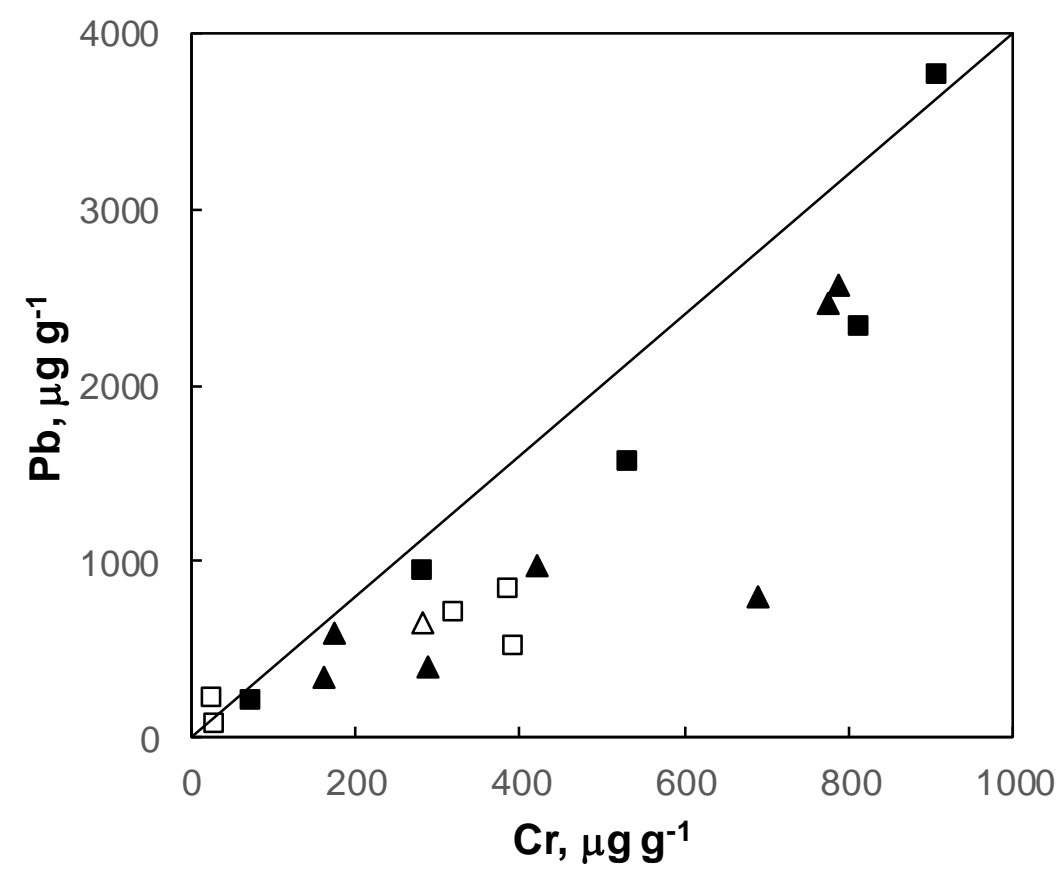

576

577 